\title{
Use of saliva to monitor meningococcal vaccine responses: proposing a threshold in saliva as surrogate of protection
}

Mariëtte B. van Ravenhorst ${ }^{1,2^{*}}$, Fiona R. M. van der Klis ${ }^{1}$, Debbie M. van Rooijen ${ }^{1}$, Elisabeth A. M. Sanders ${ }^{1,2}$ and Guy A. M. Berbers ${ }^{1}$

\begin{abstract}
Background: Mucosal antibodies against capsular polysaccharides offer protection against acquisition and carriage of encapsulated bacteria like Neisseria meningitidis serogroup C. Measurements of salivary antibodies as replacement for blood testing has important (cost-effective) advantages, particular in studies that assess the impact of large-scale vaccination or in populations in which blood sampling is difficult. This study aimed to estimate a threshold for meningococcal lgG salivary antibody levels to discriminate between unprotected and protected vaccinated individuals.

Methods: MenA-, MenC-, MenW- and MenY-polysaccharide (PS) specific IgG levels in serum and saliva from participants in a meningococcal vaccination study were measured using the fluorescent-bead-based multiplex immunoassay. Functional antibody titers in serum against the four serogroups were measured with serum bactericidal assay using rabbit complement (rSBA). A threshold for salivary lgG was determined by analysis of ROC curves using a serum rSBA titer $\geq 128$ as correlate of protection. The area under the curve (AUC) was calculated to quantify the accuracy of the salivary test and was considered adequate when $\geq 0.80$. The optimal cut-off was considered adequate when salivary lgG cut-off levels provided specificity of $\geq 90 \%$. True positive rate (sensitivity), positive predictive value, and negative predictive value were calculated to explore the possible use of salivary antibody levels as a surrogate of protection.
\end{abstract}

Results: The best ROC curve (AUC of 0.95) was obtained for MenC, with an estimated minimum threshold of MenC-PS specific salivary lgG $\geq 3.54 \mathrm{ng} / \mathrm{mL}$ as surrogate of protection. An adequate AUC ( $>0.80)$ was also observed for MenW and MenY with an estimated minimal threshold of 2.00 and $1.82 \mathrm{ng} / \mathrm{mL}$, respectively. When applying these thresholds, all (100\%) samples collected 1 month and 1 year after the (booster) meningococcal vaccination, that were defined as protective in the saliva test for MenC, MenW and MenY, corresponded with concomitant serum rSBA titer $\geq 128$ for the respective meningococcal serogroups.

Conclusion: The saliva test offers an alternative screening tool to monitor protective vaccine responses up to one year after meningococcal vaccination against MenC, MenW and MenY. Future (large) longitudinal vaccination studies evaluating also clinical protection against IMD or carriage acquisition are required to validate the currently proposed threshold in saliva.

Keywords: Neisseria meningitidis, Correlate of protection, Salivary surrogate of protection, Threshold, Conjugate meningococcal vaccine

\footnotetext{
* Correspondence: mvanravenh@gmail.com

${ }^{1}$ Centre for Infectious Disease Control, National Institute for Public Health

and the Environment (RIVM), Postbaknummer 41, Postbus 1, 3720, BA,

Bilthoven, The Netherlands

${ }^{2}$ Department of Paediatric Immunology and Infectious Diseases, Wilhelmina

Children's Hospital, University Medical Center, Utrecht, The Netherlands
}

(c) The Author(s). 2019 Open Access This article is distributed under the terms of the Creative Commons Attribution 4.0 International License (http://creativecommons.org/licenses/by/4.0/), which permits unrestricted use, distribution, and reproduction in any medium, provided you give appropriate credit to the original author(s) and the source, provide a link to the Creative Commons license, and indicate if changes were made. The Creative Commons Public Domain Dedication waiver (http://creativecommons.org/publicdomain/zero/1.0/) applies to the data made available in this article, unless otherwise stated. 


\section{Background}

Invasive meningococcal disease (IMD) remains a major public health concern due to the high mortality and morbidity. To prevent this invasive and potentially devastating infection, sufficient levels of functional antibodies in serum have been shown to be important [1]. Protective levels of antibodies in cases invasive infection are achieved only after several days [2], whereas the meningococcus can be fatal within hours after invasion in the bloodstream. Meningococcal polysaccharide (PS) conjugate vaccines (MCVs) are able to induce functional bactericidal serum antibodies that, upon binding to invading meningococci, activate complement leading to lysis of the bacteria and enhanced phagocytosis [3, 4]. Licensure of MCVs was based on serum bactericidal assay (SBA), rather than clinical efficacy studies [5]. The SBA measures antibody levels that induce complement mediated lysis of a specific target strain by incubation of two-fold serial dilutions of heat-inactivated serum with the targeted meningococcal strain in the presence of complement. A bactericidal titer of $\geq 8$ is considered as correlate of protection baby rabbit complement $[6,7]$. The use of baby rabbit complement may result in higher bactericidal titers than those obtained with human complement where a bactericidal titer of $\geq 4$ is considered as correlate of protection [8]. Therefore, a more conservative threshold of $\geq 128$ is often used in the SBA applying rabbit complement (rSBA) [1].

In the Netherlands, the annual incidence rate of IMD declined from 4.5 per 100.000 population in 2001 to 0.14 in 2014. This decline was mainly due to a gradual natural decline of the number of meningococcal serogroup B (MenB) cases [9], next to a rapid decline of meningococcal serogroup $\mathrm{C}$ (MenC) cases after introduction of the MenC conjugated vaccine in 2002 [10]. In 2002, a monovalent MenC conjugated to tetanus toxoid (MenC-TT) vaccine was offered to all children aged 118 years. At the same time, MenC-TT was introduced in the Dutch National Immunization Program (NIP) as a single vaccination for all children aged 14 months [10]. Historically, MenB was the most common serogroup in the Netherlands. However, meningococcal serogroup W (MenW) incidence is rising since the end of 2015 and currently MenW is the most common serogroup causing IMD in the Netherlands [11]. Meningococcal serogroup $\mathrm{Y}$ (MenY) disease is rare, and meningococcal serogroup A (MenA) IMD cases do not occur since 2004.

Saliva testing has previously been proposed as a potential method to monitor vaccine antibody and capsular polysaccharide antibody levels upon vaccination with conjugate vaccines, although the relationship between meningococcal salivary anticapsular antibodies and prevention of meningococcal carriage acquisition or protection against IMD is not defined [12-14]. Therefore, the relation of salivary antibodies with serum SBA titers needs to be evaluated. In addition, no previous studies aimed to determine a threshold of meningococcal specific antibodies in saliva for surrogate of protection against IMD.

In the present study, we compared MenA, MenC, MenW and MenY IgG levels in saliva with rSBA titers in serum of the corresponding serogroup in longitudinal samples taken before, one month and one year after vaccination with either the MenC-TT or tetanus toxoid conjugated quadrivalent MenACWY (MenACWY-TT) vaccine. Samples from a randomized trial aimed to determine non-inferiority of the MenACWY-TT vaccine as compared to the MenC-TT vaccine were used. With receiver operating characteristic (ROC) curve analysis of the SBA titers in serum (correlate of protection) and IgG levels in saliva (surrogate of protection), we estimated a threshold in saliva to discriminate between unprotected and protected vaccinated individuals.

\section{Methods \\ Ethical statement}

Ethical approval was obtained from the local Medical research Ethics Committees United (MEC-U). The trial was undertaken in accordance with the Good Clinical Practice guidelines established by the International Conference on Harmonization and with the Declaration of Helsinki. Written informed consent was obtained from both parents or guardians and subjects aged $\geq 12$ years before enrollment. This study was registered at the EU Clinical Trials database (EudraCT number: 2013001823-38) and at the Dutch Trial Register (www.trialregister.nl; NTR4430).

\section{Study population and design}

Serum and saliva samples of a previous phase IV, single center, open-label controlled trial were used [15]. In short, 501 healthy participants of 10, 12 and 15 years of age received either the monovalent MenC-PS conjugated to tetanus toxoid (MenC-TT, NeisVacC@) or quadrivalent MenACWY-PS conjugated to tetanus toxoid (MenACWY-TT, Nimenrix $\odot$ ) vaccine at start of the study as a booster vaccination for MenC. All participants had been primed with a single dose of MenC-TT according to the Dutch Immunization Program at 14 months (age groups 10 and 12 years) and 3 years of age (group aged 15 years). Therefore, the antibody response for MenA, MenW and MenY reflects a primary response and for MenC a booster response. Blood and saliva samples were collected before, one month and one year after the study vaccination. Saliva samples were collected using the Oracol Saliva Collection system (Malvern Medical Developments Limited). Participants were instructed to allow absorption of saliva into the swab for 
$1 \mathrm{~min}$. Saliva was immediately squeezed out the swab into a $2 \mathrm{~mL}$ spray-dried EDTA-tube (BD), and stored at ambient temperature. Within $24 \mathrm{~h}$ after collection, saliva samples were centrifuged and stored at $-80 \mathrm{C}$.

\section{Laboratory analyses}

MenA-, MenC-, MenW- and MenY-PS specific IgG levels in serum and saliva were measured using the fluorescent-bead-based multiplex immunoassay (MIA) as previously described $[12,16,17]$. The functional antibodies in serum samples were assessed as previously described $[18,19]$.

\section{Statistical analyses}

All statistical analyses were performed in the according to the protocol cohort as previously described [18]. For each serogroup, only samples with available SBA and salivary IgG results at all three time points were selected to prevent bias because antibody response after vaccination depends on antibody levels before vaccination. Participants with protective meningococcal antibodies at baseline developed higher immune responses after following the vaccination and showed better persistence of (protective) antibodies up to one year [15]. Serum and salivary antibody concentrations were log transformed before statistical analysis. Correlations were analyzed using Pearson correlation. A threshold for salivary IgG was determined by analysis with the ROC curve with an rSBA titer $\geq 128$ used as correlate of protection. The area under the curve (AUC) was calculated to quantify the accuracy of the salivary test and was considered adequate when greater than 0.80 [20]. The optimal cut-off was considered adequate if the salivary IgG cut-off levels provided a specificity of $\geq 90 \%$. To explore the possibility of the use of saliva antibody levels as surrogate of protection, true positive rate (TPR; sensitivity), positive predictive value (PPV), and negative predictive value (NPV) were calculated by classifying healthy participants with or without protective antibody levels in serum. For example, a PPV of 0.94 of the saliva test means that $94 \%$ of the healthy participants with a positive saliva teste (saliva antibody levels above the calculated cut-off) had protective rSBA titers (rSBA titer 2128 ). Please note that PPV is not used in its normal diagnostic manner. A $p$-value below 0.05 was considered statistically significant. Data were analyzed using GraphPad Prism 7.00.

\section{Results}

\section{Sample selection}

For assessment of MenC antibody levels, longitudinal serum and saliva samples for all three time points were available from 416 participants, whereas these were available for MenA, MenW and MenY from 197, 200 and 199 participants, respectively. Overall, serum rSBA titers $\geq 128$ were observed for $421 / 591$ (71\%), 863/1248 (69\%), 419/600 (70\%), and 458/597 (77\%) samples for MenA, MenC, MenW and MenY, respectively. Table 1 shows the proportion of samples with an rSBA titer $\geq 128$ for each time point and serogroup.

\section{Correlation between serum serogroup-PS specific rSBA titers and IgG levels in serum and saliva}

Overall, serum antibody-PS specific IgG levels showed significant correlations with the corresponding rSBA titers for all four serogroups (Fig. 1a-d). The strongest correlation between serum rSBA titers and IgG levels in serum was observed for MenC after the booster vaccination $(R=0.96, p$-value $<0.001$; Fig. $1 \mathrm{~b})$ compared to the other serogroups after a single primary vaccination $(R=$ $0.78,0.74$ and 0.76, for MenA, MenW and MenY, respectively, all $p$-values $<0.001$; Fig. 1a, c-d). Correlations for each time point and serogroup are shown in Table 2.

MenC-PS specific IgG in saliva correlated with MenC rSBA titers in serum $(R=0.85, p$-value $<0.001$; Fig. $2 \mathrm{~b})$. MenA, MenW and MenY salivary antibody-PS specific IgG levels showed weak to modest correlation coefficients with the corresponding serum rSBA titers $(R=0.36,0.60,0.53$, respectively, all $p$-values $<0.001$; Fig. $2 \mathrm{a}, \mathrm{c}-\mathrm{d})$. Correlations for each time point and serogroup are shown in Table 3.

\section{Estimation of threshold in saliva as correlate of protection} A significant AUC $>0.80$ was observed for MenC, MenW and MenY (Fig. 3b-d). An AUC of the ROC of 0.69 (95\% CI 0.65-0.74, $p$-value < 0.001; Fig. 3a) was observed for MenA, and the salivary test was therefore not considered adequate.

Based on the pre-specified criterium of a specificity of $\geq 90 \%$, a threshold of MenC-PS specific IgG in saliva of $3.54 \mathrm{ng} / \mathrm{mL}$ was estimated (Table 4). Using this threshold, a TPR, PPV and NPV of 0.86 (740/863), 0.95 (740/777), and $0.74(348 / 471)$ was calculated, respectively. Compared to MenC, lower salivary IgG thresholds were observed for MenW and MenY (2.00 and $1.82 \mathrm{ng} / \mathrm{mL}$, respectively). For MenW, the calculated TPR, PPV and NPV were 0.62 (258/ 419), 0.94 (258/275), and 0.50 (164/325), respectively (Table 4) and for MenY, the TPR, PPV and NPV were 0.51 (235/ 458), 0.95 (235/2548), and 0.36 (126/349), respectively.

Table 1 The proportion of samples with an rSBA titer $>=128$ for meningococcal serogroup A (MenA), C (MenC), W (MenW) and $Y$ (MenY) measured before (TO), one month (T1) and one year (T2) after the vaccination

\begin{tabular}{lllll}
\hline Serogroup & T0 N (\%) & T1 N (\%) & T2 N (\%) & All N (\%) \\
\hline MenA & $32 / 197(16)$ & $195 / 197(99)$ & $194 / 197(98)$ & $421 / 597(71)$ \\
MenC & $34 / 416(8)$ & $415 / 416(99)$ & $414 / 416(99)$ & $414 / 416(99)$ \\
MenW & $22 / 200(11)$ & $198 / 200(99)$ & $199 / 200(99)$ & $419 / 600(70)$ \\
MenY & $60 / 199(30)$ & $199 / 199(100)$ & $199 / 199(100)$ & $458 / 597(77)$ \\
\hline
\end{tabular}




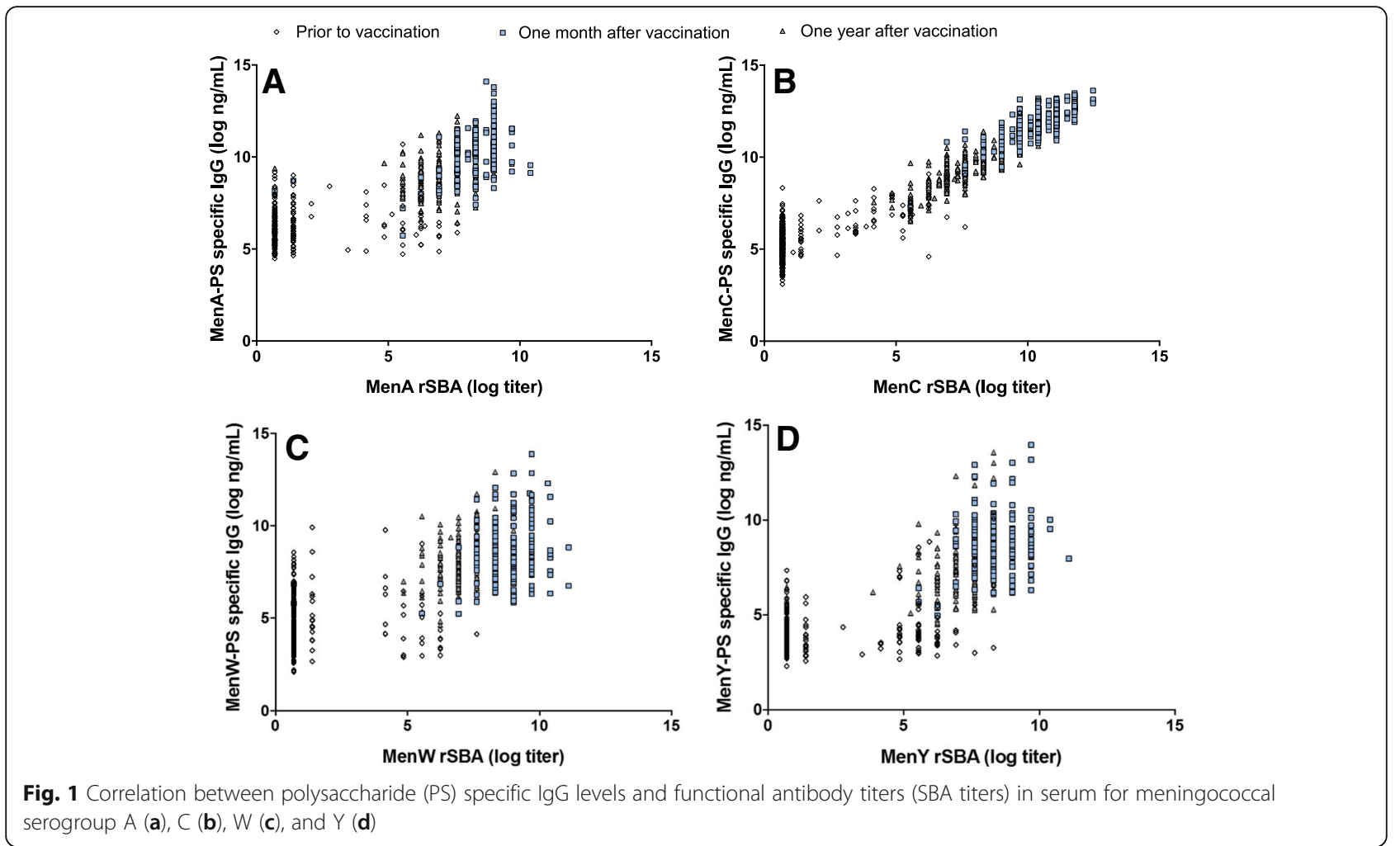

For MenC, MenW and MenY, all (100\%) samples collected 1 month and 1 year after the (booster) meningococcal vaccination with a saliva concentration above the estimated threshold showed sufficient protective serum rSBA titers for the corresponding serogroup (rSBA titer $\geq 128$ ). Of all samples collected before the vaccination, 37/ 416 (8.9\%), 17/200 (8.5\%) and 13/199 (6.5\%) with a saliva concentration above the estimated threshold had rSBA titers $<128$ for MenC, MenW and MenY, respectively.

\section{Discussion}

In this study, we showed that salivary IgG levels significantly correlated with bactericidal antibody titers in serum after both primary (MenA, MenW and MenY) and booster (MenC) vaccination. The best ROC curve (AUC of 0.95) was obtained after booster vaccination with MenC conjugate vaccine resulting in an estimated minimum threshold of MenC-PS specific salivary IgG $\geq 3.54 \mathrm{ng} / \mathrm{mL}$ as surrogate of protection in saliva. An adequate AUC (>0.80) was also observed for MenW and MenY, suggesting that the saliva test may provide a screening tool to evaluate protection up to one year after primary vaccination. The minimum threshold in saliva as surrogate of protection was estimated to be 2.00 and $1.82 \mathrm{ng} / \mathrm{mL}$ for MenW- and MenY-PS specific IgG, respectively. MenA rSBA titers in serum correlated weakly with MenA-PS specific IgG levels in serum resulting in a less fitting ROC curve with a low AUC (0.69), suggesting that the saliva test is inaccurate as surrogate of protection for MenA after primary vaccination.

Saliva testing has important (cost-effective) advantages, particularly in studies that assess the impact of large-scale vaccination campaigns or in populations where blood sampling is difficult (ie. young children or resource poor settings) [21]. Despite this advantage and the growing interest in saliva as a tool to measure

Table 2 Correlation between serogroup-polysaccharide specific lgG levels and functional antibody titers (rSBA) in serum measured before (T0), one month (T1) and one year (T2) after the vaccination

\begin{tabular}{lllll}
\hline Serogroup & T0 R $(95 \% \mathrm{Cl}), p$-value & T1 R $(95 \% \mathrm{Cl}), p$-value & T2 R $(95 \% \mathrm{Cl}), p$-value & All R (95\% Cl), $p$-value \\
\hline MenA & $0.11(-0.03-0.24), 0.14$ & $0.34(0.22-0.46),<0.001$ & $0.26(0.13-0.39), 0.002$ & $0.78(0.75-0.81),<0.001$ \\
MenC & $0.64(0.58-0.69),<0.001$ & $0.82(0.78-0.85),<0.001$ & $0.84(0.81-0.86),<0.001$ & $0.96(0.96-0.97),<0.001$ \\
MenW & $0.01(-0.13-0.15), 0.85$ & $0.23(0.09-0.35), 0.0013$ & $0.29(0.16-0.41),<0.001$ & $0.74(0.70-0.77),<0.001$ \\
MenY & $0.24(0.11-0.38), 0.001$ & $0.19(0.05-0.32), 0.007$ & $0.25(0.12-0.38), 0.001$ & $0.76(0.72-0.79),<0.001$ \\
\hline
\end{tabular}


Prior to vaccination
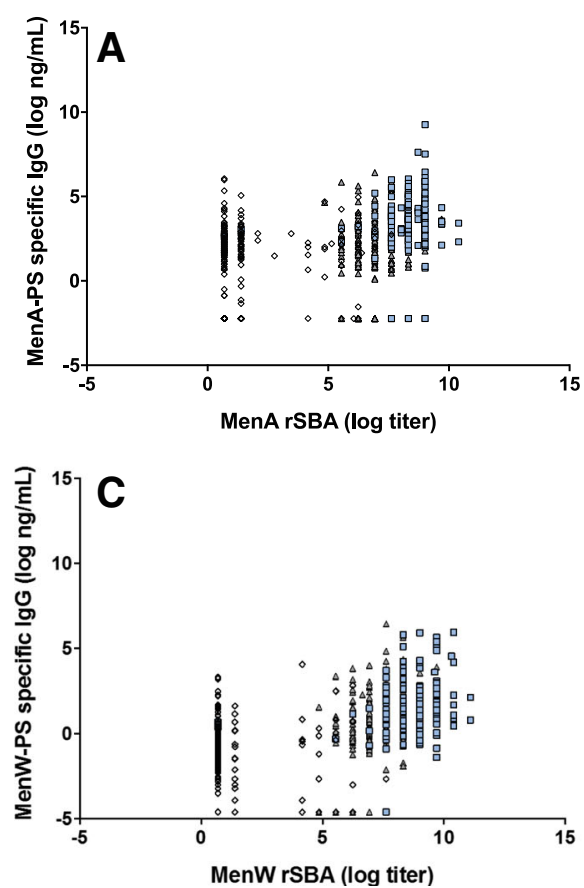

$\triangle$ One year after vaccination
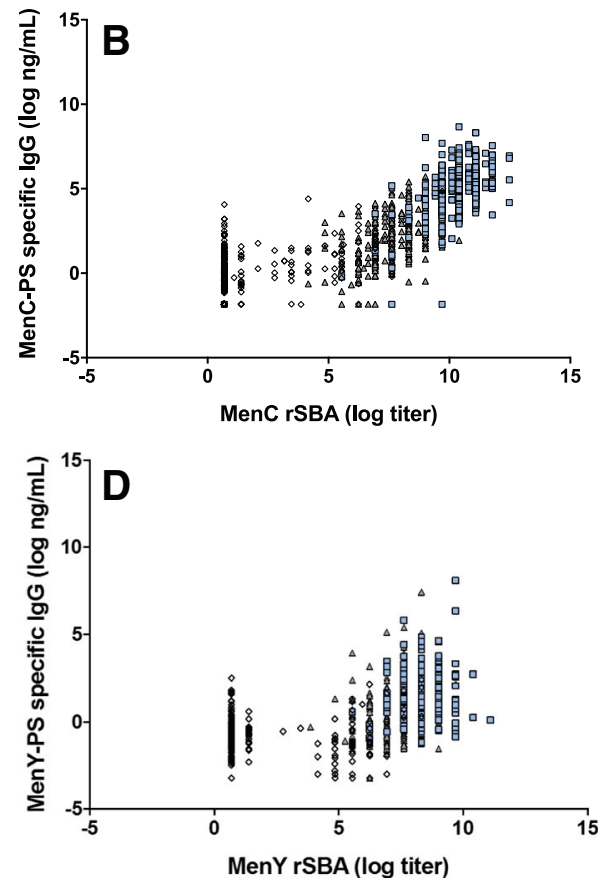

Fig. 2 Correlation between polysaccharide (PS) specific lgG levels in saliva and functional antibody titers (SBA titers) in serum for meningococcal serogroup $A(\mathbf{a}), C(\mathbf{b}), W(\mathbf{c})$, and $Y(\mathbf{d})$

antibody levels in vaccine studies, no studies have evaluated the relationship between meningococcal salivary antibody levels and clinical protection against disease. Due to the absence of complement in saliva, salivary antibodies are not able to kill the meningococcus, but may have an important role in prevention of attachment of meningococci to epithelial cells [22-24]. Previous studies indicated that saliva IgG upon meningococcal conjugate vaccination against serogroup $\mathrm{A}, \mathrm{C}, \mathrm{W}$ and $\mathrm{Y}$, rather than IgA, may be used for vaccine response monitoring because salivary IgG appears mostly serum-derived [12-14, 25] and thus reflects serum IgG levels upon vaccination that correlate with serum rSBA titers. Previously, we showed a strong correlation between IgG in serum and IgG in saliva for MenC, MenW and MenY, and a lower correlation for MenA [26]. In the current study, we confirmed good correlations between serum IgG levels and serum rSBA titers for meningococcal serogroup $\mathrm{C}, \mathrm{W}$ and $\mathrm{Y}$, in particular one month and one year after the (booster) vaccination. Therefore, salivary IgG levels might be used as surrogate marker of serum IgG antibody levels in serum. Taken together, this seems to indicate that it is possible to define a salivary antibody threshold that represents the protective status $(\mathrm{rSBA} \geq 128)$ after meningococcal vaccination.

After a single primary vaccination for MenA, MenW and MenY, we found a lower correlation between salivary IgG levels and rSBA titers as compared to a booster vaccination for MenC. There are several factors that might contribute to this lower correlation after primary vaccination. First, the ratio of total immunoglobulins relative to the $\operatorname{IgG}(\operatorname{Ig} / \operatorname{IgG})$ that enhances complement mediated-killing may be higher after booster vaccination than primary vaccination. This may indicate that after

Table 3 Correlation between sergroup-polysaccharide specific lgG levels and functional antibody titers (rSBA) in saliva measured before (T0), one month (T1) and one year (T2) after the vaccination

\begin{tabular}{lllll}
\hline Serogroup & T0 R $(95 \% \mathrm{Cl}), p$-value & T1 R $(95 \% \mathrm{Cl}), p$-value & T2 R $(95 \% \mathrm{Cl}), p$-value & All R (95\% Cl), $p$-value \\
\hline MenA & $0.11(-0.03-.025), 0.11$ & $0.11(-0.03-0.24), 0.13$ & $0.06(-0.08-0.20), 0.42$ & $0.36(0.28-0.42),<0.001$ \\
MenC & $0.37(0.29-0.45),<0.001$ & $0.54(0.47-0.61),<0.001$ & $0.53(0.46-0.60),<0.001$ & $0.85(0.84-0.87),<0.001$ \\
MenW & $0.06(-0.08-0.20), 0.37$ & $0.16(0.02-0.29), 0.02$ & $0.25(0.11-0.37), 0.001$ & $0.60(0.54-0.65),<0.001$ \\
MenY & $0.02(-0.12-0.15), 0.82$ & $0.09(-0.05-0.23), 0.19$ & $0.19(0.05-0.32), 0.007$ & $0.76(0.72-0.79),<0.001$ \\
\hline
\end{tabular}

Note. Abbreviations: $R$ Pearson correlation coefficient, $\mathrm{Cl}$ confidence interval 

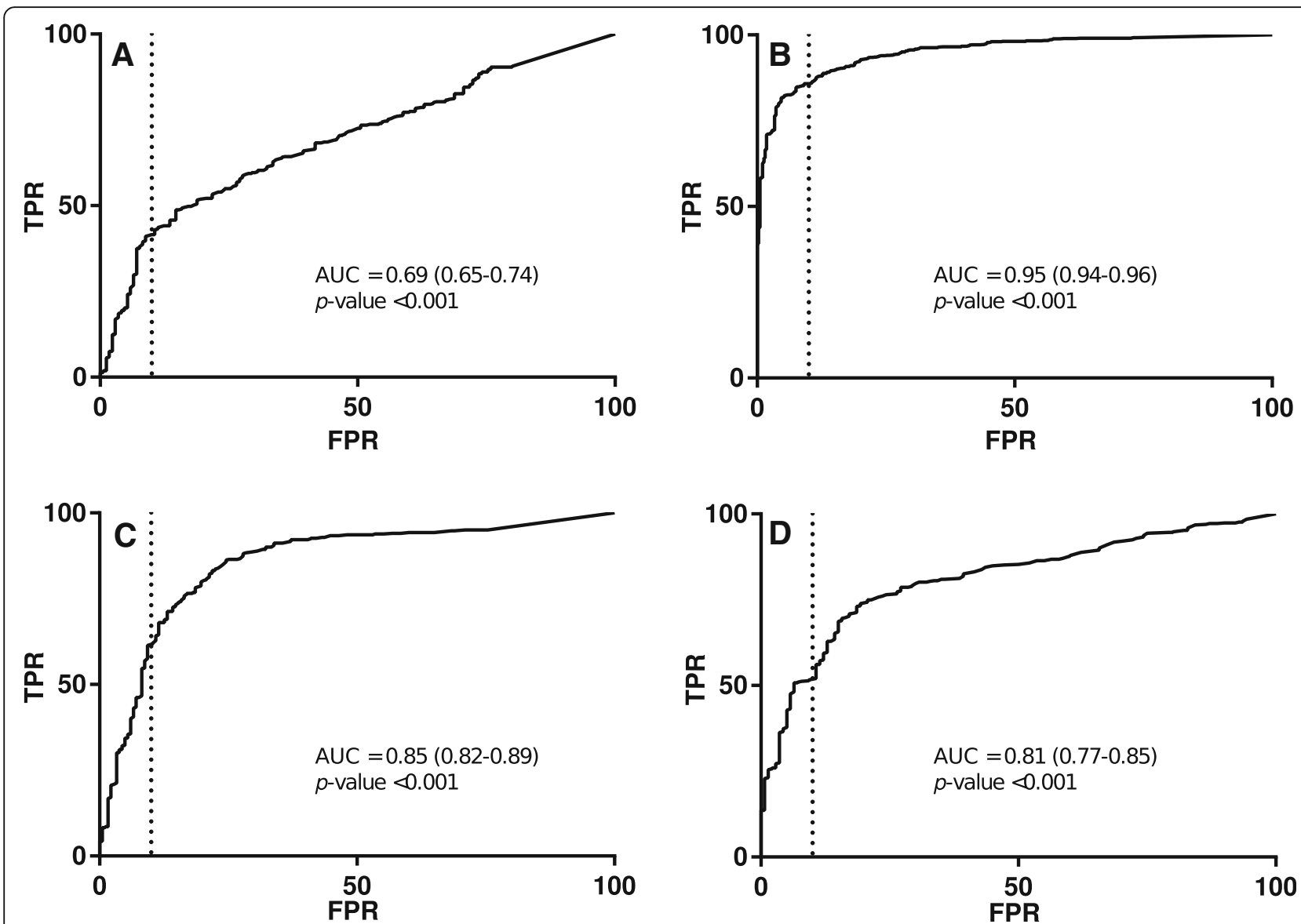

Fig. 3 Receiver operating characteristic (ROC) curve analysis: True positive rate (TPR) was plotted in the function of the false positive rate (FPR) for meningococcal serogroup A (a), C (b), W (c), and $Y(\mathbf{d})$. The estimated threshold, which provided a specificity of $\geq 90 \%$ are shown as vertical dotted lines

primary vaccination also other Ig (ie. IgA or IgM) might enhance complement-mediated killing. Second, it could be possible that previous colonization has induced salivary IgG antibodies in some individuals leading to a weaker correlation with serum IgG levels and as a consequence overestimation of protection in case of a saliva test [27, 28]. Indeed, we observed false positive saliva samples at baseline for all serogroups (samples with a saliva concentration above the estimated threshold but with an rSBA titer < 128), indicating that the saliva test is less accurate as surrogate in unvaccinated populations

Table 4 Estimated threshold for salivary lgG, true positive rate (TPR), false positive rate (FPR), positive predictive value (PPV) and negative predictive value (NPV) with ROC curve analysis with a functional antibody titer (rSBA) $>=128$ as correlate of

\begin{tabular}{llllll} 
protection & \multicolumn{7}{l}{ Serogroup } & Threshold $(\mathrm{ng} / \mathrm{mL})$ & TPR & FPR & PPV & NPV \\
\hline MenC & 3.54 & 0.86 & 0.10 & 0.95 & 0.74 \\
MenW & 2.00 & 0.62 & 0.09 & 0.94 & 0.50 \\
MenY & 1.82 & 0.51 & 0.09 & 0.95 & 0.36 \\
\hline
\end{tabular}

or not recently immunized individuals. Third, the presence of antibodies against outer-membrane proteins, which are not measured by the PS-specific saliva test, in contrast to the SBA which includes a broader spectrum of functional antibodies, might lead to an underestimation of protection via the saliva test (false negative). All three factors could explain the lower correlation after primary vaccination, which results then in a lower performance of the saliva test as surrogate of protection. For MenA, the saliva test appeared not to be accurate enough (AUC < 0.80). As previously described for MenA, cross-reactive antibodies might explain the weak correlation between salivary IgG levels and serum rSBA titers [28]. These cross-reactive antibodies probably bind to the PS in the saliva test, but are not functional and therefore not contributing in the SBA. Nevertheless, the observed high AUC for MenC, MenW and MenY seems to provide an accurate threshold to discriminate between unprotected and protected individuals (ie. rSBA titers of $<128$ and $\geq$ 128 , respectively), especially after (booster) vaccination.

Our results showed that all samples that tested positive in the saliva test were indeed also positive in the 
SBA (true positive), indicating that the saliva test provides indeed an adequate tool to monitor vaccine responses up to one year after both primary and booster meningococcal vaccination. The use of the saliva test to discriminate between protection or not would have resulted in a reduction of the amount of elaborate serum SBAs in this meningococcal vaccine study by 87,63 and $57 \%$ for MenC, MenW and MenY, respectively. Next to the advantages of taking saliva samples instead of blood, saliva $\operatorname{IgG}$ testing is easier than the SBA, less time-consuming and therefore more cost-effective. However, it has to be noted that some samples collected one month or one year after the (booster) vaccination though positive in the SBA were negative in the saliva test (false negative) ranging from $14 \%$ for MenC to $49 \%$ for MenY. The salivary threshold estimated in the current study should therefore be used as minimal threshold for surrogate of protection. Individuals with a salivary IgG levels above the estimated threshold will be protected but it is advisable to evaluate also serum SBA titers for all samples with a salivary IgG level below this minimal threshold.

A limitation of this study was that only samples of children aged $10-15$ years were used here to identify the salivary thresholds. Therefore, these salivary thresholds as surrogate of protection have to be validated in other large meningococcal vaccine trials, preferably studies that include participants with a wide age range. In addition, samples were collected only up to one year after vaccination. Whether saliva samples can be used as a surrogate of protection in the long term after vaccination has to be investigated as well.

\section{Conclusions}

In conclusion, the saliva test offers an alternative tool to screen vaccine responses up to one year after meningococcal vaccination against serogroups $\mathrm{C}, \mathrm{W}$ and $\mathrm{Y}$, with a high specificity and good sensitivity in particular after booster vaccination. Before the saliva test can be used as surrogate of protection for clinical protection against IMD, it is required to validate the proposed thresholds of the current study in future (large) longitudinal clinical meningococcal vaccination studies.

\footnotetext{
Abbreviations

AUC: Area under the curve; IMD: Invasive meningococcal disease: MCVs: Meningococcal polysaccharide conjugate vaccines; MenA: Meningococcal serogroup A; MenACWY-TT: Tetanus toxoid conjugate quadrivalent MenACWY vaccine; MenC: Meningococcal serogroup C; MenC-TT: Tetanus toxoid conjugated monovalent MenC vaccine; MenW: Meningococcal serogroup W; MenY: Meningococcal serogroup Y; NPV: Negative predictive value; PPV: Positive predictive value; PS: Polysaccharide; ROC: Receiver operating characteristic; rSBA: Serum bactericidal assay using rabbit complement; TPR: True positive rate
}

\section{Acknowledgements}

We thank the families and children who participated in the study. Furthermore, we thank Rutger Schepp for his help with interpreting the data.

\section{Funding}

This study was funded by the Dutch Ministry of Health. The funder had no role in study design, data collection and analysis, decision to publish, or preparation of the manuscript.

\section{Availability of data and materials}

The datasets generated and analysed during the current study are not publicly available due to confidential patient data but are available anonymous from the corresponding author on reasonable request.

\section{Authors' contributions}

MBVR, FRMvdK, EAMS and GAMB were involved in the conception, planning and study design. MBvR and DMvR performed the laboratory analyses. MBvR performed statistical analysis. MBvR, FRMvdK, EAMS and GAMB wrote the manuscript. All authors agreed to submit for publication. All authors read and approved the final manuscript.

\section{Ethics approval and consent to participate}

Ethical approval was obtained from the local Medical research Ethics Committees United (MEC-U). The trial was undertaken in accordance with the Good Clinical Practice guidelines established by the International Conference on Harmonization and with the Declaration of Helsinki. Written informed consent was obtained from both parents or guardians and subjects aged $\geq 12$ years before enrollment. This study was registered at the EU Clinical Trials database (EudraCT number: 2013-001823-38) and at the Dutch Trial Register (www.trialregister.nl; NTR4430).

\section{Consent for publication}

Not applicable.

\section{Competing interests}

MBvR, FRMvdK, DMvR, and GAMB report no conflict of interest. EAMS declares to have received research grants from GlaxoSmithKline and from Pfizer.

\section{Publisher's Note}

Springer Nature remains neutral with regard to jurisdictional claims in published maps and institutional affiliations.

Received: 14 November 2017 Accepted: 20 December 2018 Published online: 05 January 2019

\section{References}

1. Andrews N, Borrow R, Miller E. Validation of serological correlate of protection for meningococcal $C$ conjugate vaccine by using efficacy estimates from postlicensure surveillance in England. Clin Diagn Lab Immunol. 2003;10(5):780-6.

2. Erlich KS, Congeni BL. Importance of circulating antibodies in protection against meningococcal disease. Human vaccines \& immunotherapeutics. 2012;8(8):1029-35.

3. Richmond P, Borrow R, Miller E, Clark S, Sadler F, Fox A, Begg N, Morris R, Cartwright K. Meningococcal serogroup C conjugate vaccine is immunogenic in infancy and primes for memory. J Infect Dis. 1999;179(6):1569-72.

4. Granoff DM. Relative importance of complement-mediated bactericidal and opsonic activity for protection against meningococcal disease. Vaccine. 2009;27(Suppl 2):B117-25.

5. Miller E, Salisbury D, Ramsay M. Planning, registration, and implementation of an immunisation campaign against meningococcal serogroup $C$ disease in the UK: a success story. Vaccine. 2001.

6. Goldschneider I, Gotschlich EC, Artenstein MS. Human immunity to the meningococcus. II Development of natural immunity. The Journal of experimental medicine. 1969;129(6):1327-48.

7. Maslanka SE, Gheesling LL, Libutti DE, Donaldson KB, Harakeh HS, Dykes JK, Arhin FF, Devi SJ, Frasch CE, Huang JC, et al. Standardization and a multilaboratory comparison of Neisseria meningitidis serogroup a and $C$ serum bactericidal assays. The Multilaboratory Study Group. Clinical and diagnostic laboratory immunology. 1997;4(2):156-67. 
8. Borrow R, Andrews N, Goldblatt D, Miller E. Serological basis for use of meningococcal serogroup C conjugate vaccines in the United Kingdom: reevaluation of correlates of protection. Infect Immun. 2001;69(3):1568-73.

9. Bijlsma MW, Bekker V, Brouwer MC, Spanjaard L, van de Beek d, van der Ende A. Epidemiology of invasive meningococcal disease in the Netherlands, 1960-2012: an analysis of national surveillance data. Lancet Infect Dis. 2014;14(9):805-1012.

10. de Greeff SC, de Melker HE, Spanjaard L, Schouls LM, van Derende A. Protection from routine vaccination at the age of 14 montis with meningococcal serogroup C conjugate vaccine in the Netherlands. Pediatr Infect Dis J. 2006;25(1):79-80.

11. Knol MJ, Ruijs WL, Antonise-Kamp L, de Melker HE, van der Ende A. Implementation of MenACWY vaccination because of ongoing increase in serogroup W invasive meningococcal disease, the Netherlands, 2018. Euro Surveillance. 2018;23(16)

12. Stoof SP, van der Klis FR, van Rooijen DM, Bogaert D, Trzcinski K, Sanders EA, Berbers GA. Salivary antibody levels in adolescents in response to a meningococcal serogroup $C$ conjugate booster vaccination nine years after priming: systemically induced local immunity and saliva as potentia surveillance tool. Vaccine. 2015;33(32):3933-9.

13. Zhang $\mathrm{Q}$, Choo S, Everard J, Jennings R, Finn A. Mucosal immune responses to meningococcal group $C$ conjugate and group a and $C$ polysaccharide vaccines in adolescents. Infect Immun. 2000:68(5):2692-7.

14. Barnes GK, Workalemahu B, Kristiansen PA, Beyene D, Merdekios B, Fissiha P, Aseffa A, Caugant DA, Naess LM. Salivary and serum antibody response against Neisseria meningitidis after vaccination with conjugate polysaccharide vaccines in Ethiopian volunteers. Scand J Immunol. 2016;84(2):118-29.

15. van Ravenhorst MB, van der Klis FRM, van Rooijen DM, Knol MJ, Stoof SP, Sanders EAM, Berbers GAM. Meningococcal serogroup C immunogenicity, antibody persistence and memory B-cells induced by the monovalent meningococcal serogroup $C$ versus quadrivalent meningococcal serogroup ACWY conjugate booster vaccine: a randomized controlled trial. Vaccine. 2017;35(36):4745-52

16. de Voer RM, van der Klis FR, Engels CW, Rijkers GT, Sanders EA, Berbers GA. Development of a fluorescent-bead-based multiplex immunoassay to determine immunoglobulin $\mathrm{G}$ subclass responses to Neisseria meningitidis serogroup a and C polysaccharides. Clinical and vaccine immunology : CVI. 2008;15(8):1188-93.

17. Lal G, Balmer P, Joseph H, Dawson M, Borrow R. Development and evaluation of a tetraplex flow cytometric assay for quantitation of serum antibodies to Neisseria meningitidis serogroups a, C, Y, and W-135. Clin Diagn Lab Immunol. 2004;11(2):272-9.

18. van Ravenhorst MB, van der Klis FRM, van Rooijen DM, Knol MJ, Stoof SP, Sanders EAM, Berbers GAM. Meningococcal serogroup C immunogenicity, antibody persistence and memory B-cells induced by the monovalent meningococcal serogroup $C$ versus quadrivalent meningococcal serogroup ACWY conjugate booster vaccine: a randomized controlled trial. Vaccine. 2017.

19. van Ravenhorst MB, van der Klis FRM, van Rooijen DM, Sanders EAM, Berbers GAM. Adolescent meningococcal serogroup a, W and $Y$ immune responses following immunization with quadrivalent meningococcal a, C, W and $Y$ conjugate vaccine: optimal age for vaccination. Vaccine. 2017.

20. Hanley JA, McNeil BJ. The meaning and use of the area under a receiver operating characteristic (ROC) curve. Radiology. 1982;143(1):29-36.

21. Fylkesnes K, Kasumba K. The first Zambian population-based HIV survey: saliva-based testing is accurate and acceptable. Aids. 1998;12(5):540-1.

22. Marcotte $H$, Lavoie MC. Oral microbial ecology and the role of salivary immunoglobulin a. Microbiology and molecular biology reviews : MMBR. 1998;62(1):71-109.

23. Zhang Q, Finn A. Mucosal immunology of vaccines against pathogenic nasopharyngeal bacteria. J Clin Pathol. 2004;57(10):1015-21.

24. Horton RE, Stuart J, Christensen H, Borrow R, Guthrie T, Davenport V, Finn A, Williams NA, Heyderman RS, Team AS. Influence of age and carriage status on salivary IgA to Neisseria meningitidis. Epidemiol Infect. 2005;133(5):883-9.

25. Borrow R, Fox AJ, Cartwright K, Begg NT, Jones DM. Salivary antibodies following parenteral immunization of infants with a meningococcal serogroup a and C conjugated vaccine. Epidemiol Infect. 1999;123(2):201-8.

26. van Ravenhorst MB, den Hartog G, van der Klis FRM, van Rooijen DM, Sanders EAM, Berbers GAM. Induction of salivary antibody levels in Dutch adolescents after immunization with monovalent meningococcal serogroup C or quadrivalent meningococcal serogroup a, C, W and Y conjugate vaccine. PLoS One. 2018;13(4):e0191261.
27. Glode MP, Robbins JB, Liu TY, Gotschlich EC, Orskov I, Orskov F. Crossantigenicity and immunogenicity between capsular polysaccharides of group C Neisseria meningitidis and of Escherichia coli K92. J Infect Dis. 1977;135(1):94-104.

28. Vann WF, Liu TY, Robbins JB. Bacillus pumilus polysaccharide cross-reactive with meningococcal group a polysaccharide. Infect Immun. 1976;13(6): 1654-62.

\section{Ready to submit your research? Choose BMC and benefit from:}

- fast, convenient online submission

- thorough peer review by experienced researchers in your field

- rapid publication on acceptance

- support for research data, including large and complex data types

- gold Open Access which fosters wider collaboration and increased citations

- maximum visibility for your research: over $100 \mathrm{M}$ website views per year

At $\mathrm{BMC}$, research is always in progress.

Learn more biomedcentral.com/submissions 